\title{
A Study of Micro-blog Marketing Based on Consumer Purchasing Intention
}

\author{
Qinwen Dong \\ SHU-UTS SILC Business School \\ Shanghai University \\ Shanghai, China \\ E-mail: wennie_dong@163.com
}

\author{
Xiaosong Zheng* \\ SHU-UTS SILC Business School \\ Shanghai University \\ Shanghai, China \\ E-mail: xiaosong.zheng@shu.edu.cn
}

\begin{abstract}
Network media is playing a more and more important role in people's daily life. Micro-blog breaks through the traditional media communication mode and becomes the real grassroots media with its diversification and populism of the main body, and liberates the people's right of speech greatly by its simple content expression and convenient and diversified way of transmission. Micro-blog marketing is a new marketing method. It is more targeted than ordinary promotion ads or link ads through the Micro-blog platform, and it also reduces the audience's resistance psychology. Micro-blog marketing has become an inevitable choice of social media marketing for modern enterprises. This paper analyzes the characteristics of Micro-blog, Micro-blog marketing and consumers' willingness to buy. By using the data analysis method of questionnaire survey, this paper gives some practical and effective strategies and operation modes that combine the purchase intention of consumers under different Micro-blog marketing strategies.
\end{abstract}

Keywords-Micro-blog; Marketing; Consumer; Purchase intention

\section{INTRODUCTION}

In March 2006, the US website Twitter launched a new service, this new 140-character information sharing method has quickly received the popularity of users, ushering in a new era of social media. With the popularity of Micro-blog, Sina launched its beta version in August 2009. Subsequently, the major portal sites such as Micro-blog such as Phoenix New Media Micro-blog, people's Network Micro-blog have online, showing a school of development in full swing in China.

According to <No. 41 Statistical Report on Internet Development in China> [1], published by the China Internet Network Information Center (CNNIC), as of December 2017, the number of Internet users in China had reached 772 million, with an Internet penetration rate of $55.8 \%$, of which 316 million Micro-blog users. Compared with mobile phone Microblog users alone, by the end of 2017, it had reached 286 million and $38.0 \%$ of mobile Internet users (see fig. 1), up to $18.9 \%$ from 2016. This shows that Micro-blog has become one of the fastest growing social media applications and mobile phone applications, fully showing its huge market potential.

\begin{tabular}{|c|c|c|c|c|c|}
\hline TABLE I & \multicolumn{5}{|c|}{$\begin{array}{l}\text { UTILIZATION RATE OF INTERNET APPLICATIONS AMONG } \\
\text { CHINESE INTERNET USERS }\end{array}$} \\
\hline & \multicolumn{2}{|c|}{2017.12} & \multicolumn{2}{|c|}{2016.12} & \multirow[b]{2}{*}{$\begin{array}{l}\text { Annual } \\
\text { rate of } \\
\text { growth }\end{array}$} \\
\hline Application & $\begin{array}{c}\text { Users } \\
\text { amount } \\
\text { (million) }\end{array}$ & $\begin{array}{l}\text { Internet } \\
\text { users' } \\
\text { utilization } \\
\text { rate }\end{array}$ & $\begin{array}{c}\text { Users } \\
\text { amount } \\
\text { (million) }\end{array}$ & $\begin{array}{l}\text { Internet } \\
\text { users' } \\
\text { utilization } \\
\text { rate }\end{array}$ & \\
\hline Weibo & 316.01 & $40.9 \%$ & 271.43 & $37.1 \%$ & $16.4 \%$ \\
\hline Weibo app & 286.34 & $38.0 \%$ & 240.86 & $34.6 \%$ & $18.9 \%$ \\
\hline
\end{tabular}

Micro-blog, as social media, continued its in-depth distribution of short video and live mobile streaming in 2017, driving continued growth in user usage to $40.9 \%$, up $3.8 \%$ from December 2016. In 2017, the functions of various social platforms are becoming more and more perfect, and the influence of media communication is increasing significantly.

Social networks are becoming an ecological platform for "connecting everything". Social applications are becoming increasingly rich, from timely communication to news push, live video, payment transactions, games, public services, and so on, can be achieved in social applications, covering a wide range of the development trend of the platform is obvious. User stickiness is increasing. At the same time, social networks have accelerated the diversification of Internet business models, with social-based marketing services and mobile advertising becoming the most active areas.

According to the CNNIC, China's online advertising market was 295.7 billion yuan in 2017, up 28. $8 \%$ from last year, up from the previous year. This shows that the online advertising market in China has further matured, the market structure has tended to be stable, and the budget of advertisers is in line with the current situation.

According to the data from an Internet users' behavior monitoring system called iUserTracker [2], as of July 2018, Micro-blog services monthly coverage of more than 510 million, when the growth slowed down, the development went into a mature stage. As a social media platform, Micro-blog has become one of the main services for Internet users to obtain news and information.

Based on the above realistic background, this paper analyzes consumers' consumption behavior preferences and purchase intentions through questionnaire survey analysis, and 
comes up with the most suitable substantive Micro-blog marketing suggestions and strategies for consumers' purchase intentions.

\section{LITERATURE REVIEW}

It can better spread to fans of enterprise product confidence, increase brand exposure, promote publicity, and then achieve the purpose of marketing by establishing a good corporate image and product image. Zhao (2012) states that the development of Micro-blog is necessary [3]. The development of network marketing environment, the uptake of users' information, the feedback of consumers' opinions, the products and services of enterprises, the promotion of business, the determination of target customers and the reduction of marketing cost are the main driving factors of Micro-blog marketing. Li (2017) thinks that the long-term effect of enterprise Micro-blog marketing is composed of short term marketing activities [4]. It is necessary to study the marketing effect of single Micro-blog. As a new marketing model, Micro-blog marketing has unparalleled advantages over other marketing strategies. The characteristics of Micro-blog, such as strong interaction, low cost, rapid spread and three-dimensional mode, are all its strength as a marketing theme (Zhang, 2012). However, there are also some drawbacks of Micro-blog marketing [5]. Micro-blog marketing is divided into personal and corporate Micro-blog marketing. Enterprises often use Micro-blog to increase their visibility through Micro-blog, and finally achieve the goal of selling their own products. Liu (2013) states that this marketing way pays attention to the value transmission, the content interaction, the system layout, the accurate localization [6]. However, many enterprises have some misunderstandings and difficulties in the implementation of Micro-blog marketing process. Chen (2015) thinks that Micro-blog is merely a publishing platform for enterprise information and it lacks interactive communication with fans. Information released by companies is too casual [7]. The improper use of Micro-blog marketing methods can easily lose fans. Combined with the process of consumer purchase and the factors influencing the purchase intention, this paper will further explore the relationship between Micro-blog marketing mode and consumer purchase intention.

\section{RESEARCH METHOD AND DATA COLLECTION}

\section{A. Objective}

With the continuous accumulation of users and the rapid development of user groups, the role of Micro-blog as a platform for information dissemination and sharing is changing quietly. More and more enterprises begin to use Micro-blog as a marketing tool.

In order to know what attitude people held for the Microblog marketing this new model, understand and analyze how the enterprise should promote their Micro-blog marketing and increase their brand influence. What factors will cause the difference of consumers' purchase and will affect the effect of Micro-blog marketing? We use the method of questionnaire survey to investigate and analyze the consumer purchase intention.

\section{B. Questionnaire design and sample selection}

The formulation of the initial questionnaire mainly refers to the theoretical basis and research results of relevant fields at home and abroad, and according to the domestic network economy environment, the characteristics of Micro-blog and the interview results of Micro-blog users, it is modified and supplemented appropriately. The questionnaire includes three parts: the basic information of interviewees, the use of Microblog and the acceptance of Micro-blog marketing.

So far, college students have become one of the most representative groups of Micro-blog users in our country. They have rich knowledge, a certain degree of autonomy in consumer behavior, and are more receptive to new things. They have certain network consumptive experience and ability, which is an important target customer group of the enterprise Micro-blog marketing. Kuehn's research in 1996 [3] found that using students as a sample can draw a more reliable conclusion, many foreign online shopping behavior research current affairs also use students as a sample [4]. Therefore, this paper takes the college students as the main research object. They are not only more familiar with the network, but also have Micro-blog accounts, which is more helpful for us to analyze the relationship between Micro-blog marketing and consumers' willingness to buy. The purpose of this paper is to explore more comprehensively the characteristics of consumers' purchasing behavior in the era of web2.0 so the consumers are not distinguished between those who have already participated in Micro-blog shopping and those who are potential purchasers.

\section{Investigation method}

This paper collects data by means of network survey because Micro-blog is a network user behavior on network platform. Firstly, we published our questionnaire on a professional survey website called "questionnaire star", then sent them to interviewees via Micro-blog websites led by Sina Micro-blog, and instant messaging software led by WeChat. Moreover, several kinds of methods are used such as snowball sampling, target type and nearest sampling etc. Investigations were conducted from April 1st 2018 to April 10th 2018. During the design process we limited the same address page to ensure that data were reliable.

\section{Sample structure and result analysis}

273 questionnaires were recovered from this survey, which excluded 68 questionnaires that could not continue answering related questions without Micro-blog, and 169 complete questionnaires were finally obtained.

After statistical analysis of questionnaire data we found that most people already started using Micro-blog and used more than 1 year ago and. We noticed that Micro-blog's age group is concentrated between 21 and 25 years -- some people have more access to Internet than others, familiar with networks and often used, willing to try and compare quickly with new things, focusing more on individuality and fashion; More efficient and convenient lifestyle. Although college students are the main survey group, Internet marketing is suitable for people of all ages [3]. Therefore, the results of the survey are universal. 
In this survey we can see that $92.9 \%$ users prefer to use Micro-blog as mobile clients or mobile phones that are far larger than users who prefer Internet users. In this fast consuming era, people's pace of life has accelerated, coupled with limited conditions such as learning and work, people can browse Micro-blog pages relatively few times using computers. Mobile devices such as mobile phones and tablet computers have gained more modern people's favor because of their portability privacy and lightweight etc. Therefore, more debris time is occupied by mobile Internet, not rigidly adhere to time location, can browse or publish Micro-blog anytime anywhere, which provides a solid foundation for enterprises to carry on Micro-blog marketing.

The reasons and contents of consumers favor Micro-blog

People willing to use Micro-blog mainly because of its rich information, wide range of communication and strong interactivity, which shows that modern people have high demand and initiative for information, but this face-to-face communication is weakened. People tend to gain information in such virtual world and closer to each other. In terms of content, generally speaking netizens will focus more on entertainment, friends' dynamics and literary arts, which adding more than $50 \%$ respondents to respondents. Currently Micro-blog users who actively focus on sales information accounted for only $6.51 \%$ but I think this is a very optimistic news for enterprises interested in doing Micro-blog marketing. This represents Micro-blog already has such a relatively fixed group will pay attention to sales information prove that people's consciousness is updating and everyone is gradually adapting to new shopping consumption patterns. China's Internet users base large Micro-blog marketing development space is also self-evident.

\section{Internet users' views on Micro-blog marketing}

We analyzed netizens' views on Micro-blog marketing and found that most users still hold positive and positive attitude towards Micro-blog marketing effect. From fig.2, most of the users think it "obvious effect" or "limited effect", this part thinks "obvious effect" user will be enterprise future Microblog marketing should vigorously develop latent audience.

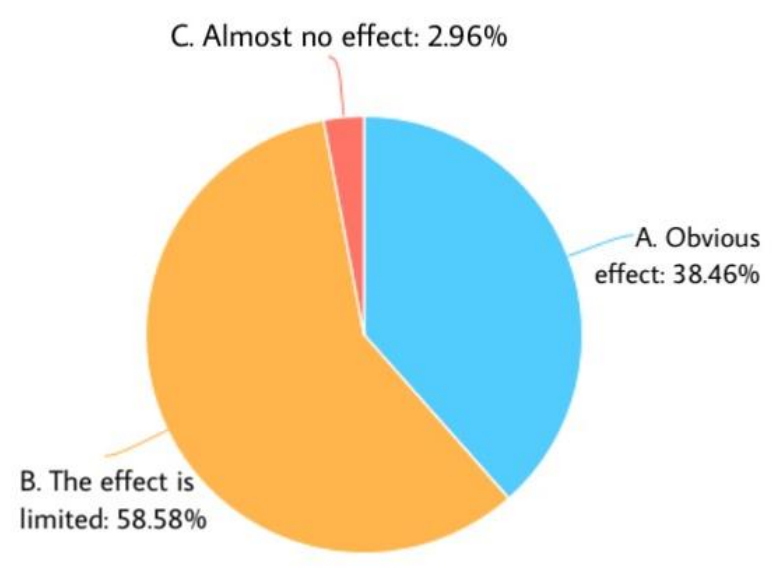

Fig. 1 Internet users' views on Micro-blog marketing

\section{RESUlts AND Discussions}

According to other findings of this questionnaire we draw some constructive suggestions and substantive strategies helpful to enterprises Micro-blog marketing for enterprises to adopt.

\section{A. Using professionalism and celebrity effects}

Whether traditional network marketing mode or Micro-blog marketing needs constantly sharing among users so that information in cyberspace increases exponentially in visibility can be unable to achieve integration effect under line. Like all mechanisms of communication, celebrities and ordinary people have different professional roles, roles and influence and diffusion ability in this process.

According to our questionnaire, we can see Micro-blog users prefer to focus on friends and relatives and celebrities (see fig.3), where families are scattered while celebrities are relatively concentrated. There are also more people who believe that celebrity effects will boost their use of Micro-blog while popular search topics attract netizens' attention (see fig.4). Thus, utilizing celebrity effect is an important way to promote Micro-blog, which helps Micro-blog to improve popularity, attract fans, expand influence, build image and stimulate consumption. Therefore, the effective use of celebritiesordinary people's bipolar communication mode linked together marketing can get twice the result with half the effect.

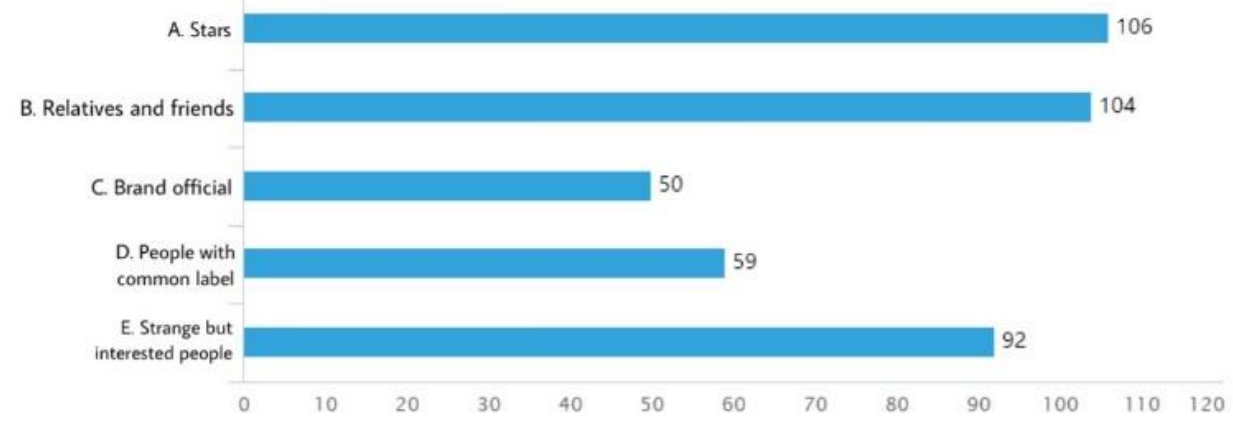

Fig. 2 Micro-blog user focus demographic Chart 


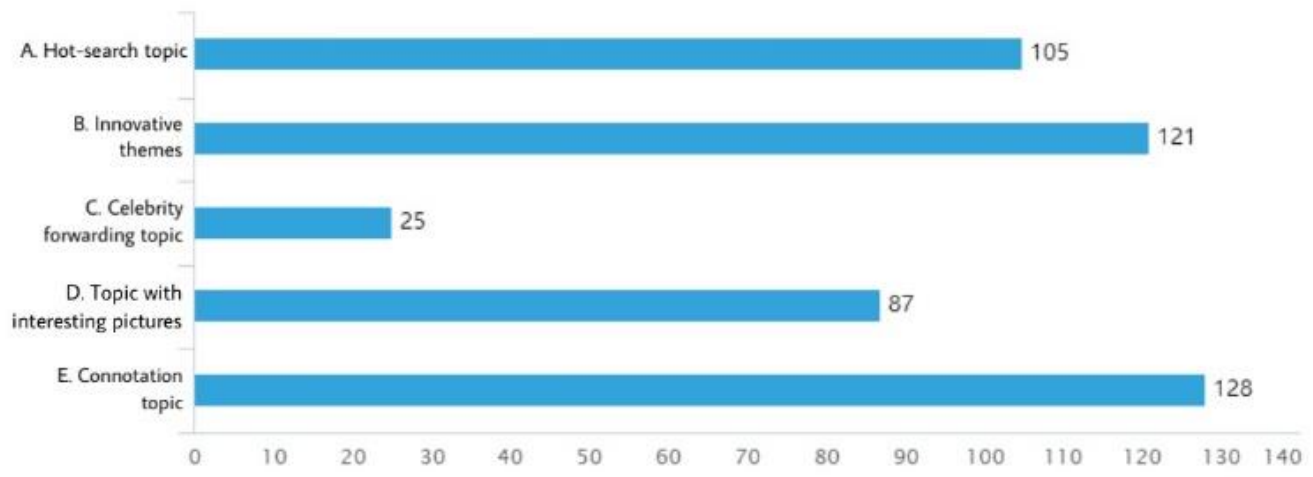

Fig. 3 Micro-blog content interested in netizens

\section{B. Correct handling of negative information and response to crisis public relations}

According to our questionnaire we find that most respondents believe that negative news diffusion is a bigger problem in Micro-blog marketing which obviously affects directly users' goodwill and trust in enterprises and seriously undermining consumer enthusiasm for buying.

For dealing with negative information, I think the following points are very important:

1) Firstly, give attention to the first time, communicate with Micro-blog master who publish negative information and understand what happened quickly report to enterprise crisis management team.

2) Whether the question whether the blogger responds is true or not, it should sum up its content assessment problem, form coping scheme, and publish bad information once in the process of using Micro-blog's external response.

3) Thirdly, seeking credible expert associations and government departments to endorse seeking celebrities as a party of crisis third party voice seems crucial because it is more convincing than organizational itself.

4) Rumors, false or false information appeared in Microblog should not be suppressed recklessly but should be exposed at first time and organize experts to suppress rumors.

5) If necessary, individuals or organizations maliciously maligned shall adopt legal means to protect their rights and interests.

The appearance of Micro-blog makes social media reaching their consumers in unprecedented ways. The enterprise establishes Micro-blog carries on the marketing, should not only use the technique to create the dissemination opportunity and the dissemination value, but should also grasp every opportunity which communicates directly with the audience, fully utilizes the self-media ability to expresses the selfposition, turns the crisis into the turning point. This is also what today's consumers prefer to buy "business development mode. In Micro-blog era, enterprises in order to enhance consumer buying willingness should focus on preparing to respond to challenges actively.

\section{Capture users with hot topics}

Micro-blog, by its very nature, is self-media, with the content is published by the user himself. But as far as influence is concerned, since the media advocated openness and humanization, it has also been scattered a part. Take Sina Micro-blog as an example, users can only accept Micro-blog published by their interesting object, and there are two ways to find new objects of interest: search users with keywords through Sina Micro-blog's search engine, or click on the publisher of the original Micro-blog by following the user's forwarded Micro-blog. The subjective initiative of the user occupies a dominant position and plays an active role as a "seeker" in either way.

When people use search engines or browse professional websites, they usually have a strong purpose. While browsing the Micro-blog, it is often in a random state of uncertainty. We looked at how often users focused on "hot searches" and how often they searched for specific topics and users. The results were as follows [see fig. $5 \& 6$ ]:

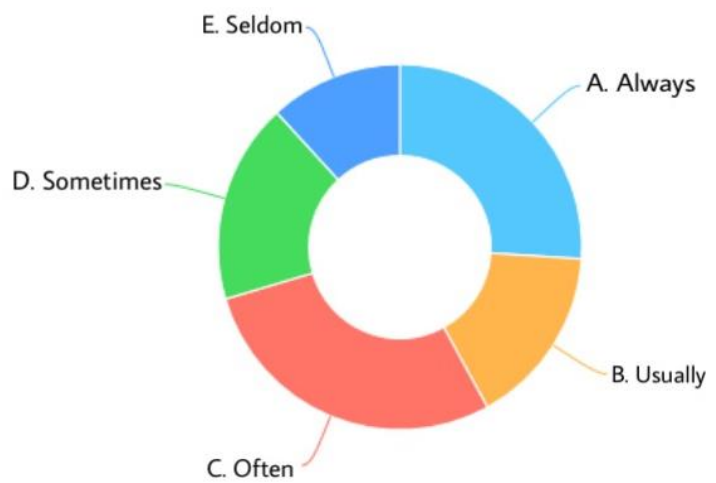

Fig. 4 The frequency of users pay attention to "hot searches" 
TABLE II

F THE FREQUENCY OF USERS USES MICRO-BLOG TO SEARCH FOR SPECIFIC TOPICS

\begin{tabular}{|l|c|c|}
\hline \multicolumn{1}{|c|}{ Choice } & Number & Percentage \\
\hline A. Always & 24 & $14.2 \%$ \\
\hline B. Usually & 40 & $23.67 \%$ \\
\hline C. Often & 56 & $33.14 \%$ \\
\hline D. Sometimes & 29 & $17.16 \%$ \\
\hline E. Seldom & 20 & $11.83 \%$ \\
\hline \multicolumn{1}{|c|}{ Total } & 169 & \\
\hline
\end{tabular}

In our questions about how often users use "Micro-blog hot search", we found that more than $40 \%$ of users "always" and "usually" browse popular search pages [see fig.6]. Among Sina Micro-blog users surveyed, 33.14\% of users "often searched for specific topics"[see fig.7]. Combining the above two tables and graphs, we draw the following conclusion: most Sina Micro-blog users only browse the Micro-blog posted by others at random on the website, and do not have a specific purpose, nor do they often search for specific topics. It is precisely because Micro-blog users do not have their own browsing process, which makes the Micro-blog site guidance function plays a huge role. In the huge information flow of tens of millions of Micro-blog websites every day, the guiding function of the website provides the index and direction for users, so that the blind browsing users can quickly pay attention to some Micro-blog.

The "24-hour popular Micro-blog" on the right side of Micro-blog's homepage is not only within the scope of visual interest of the page, but also easy to attract users' attention, and it also links the content, retweeter and number of retweets of Micro-blog completely. Through the analysis, we find that the hot topic of Micro-blog is almost all the hot topics in today's society. Through the aggregative power of Micro-blog website itself, Micro-blog can capture the user that is in "popular search" quickly, to achieve the effect that enhances brand influence and propagate power thereby.

Moreover, Micro-blog records users' real daily needs, thoughts, hobbies, moods, experiences, and so on, and each user automatically becomes the disseminator of information. Through these Micro-blog, enterprises can obtain more consumer feedback information and in-depth understanding of consumer behavior. So as to formulate a more optimized or more appropriate product strategy and marketing strategy [5]. On the other hand, the search function, thematic function and group function of Micro-blog create conditions for the classification and aggregation of scattered information, through which enterprises can screen and comb the customer groups, enhance the existing customer loyalty, and search for potential customers.

\section{CONCLUSION AND Discussion}

Overall review of the full text, the purpose of the author is to put forward a complete set of feasible strategies of Micro-blog marketing in China. In order to achieve this goal, the author first clarify the concept and characteristics of Micro-blog itself, which is the basis of Micro-blog marketing. Combined with the questionnaire survey method and the mathematical model summarized, this paper gives the most suitable decision-making recommendations for the current development of Micro-blog and consumers' willingness to purchase.

The development time of Micro-blog in China is not long, so what is the effect of Micro-blog marketing? whether the Microblog marketing advice given in this paper is really suitable for the whole network environment or not, it only stays at the level of theoretical analysis. There are no more actual results or more data to prove them. Micro-blog is still a new thing in our country, with its continuous development, there are bound to be more problems.

For enterprises, the focus at this stage should be to establish the awareness of Micro-blog marketing, and this article is just a brick to draw jade, sketching out the blueprint of Micro-blog marketing. In the future, with the entry of more multimedia, the competition among the major Micro-blog websites will be intensified, and the problems in marketing technology will become more and more prominent. The value of Micro-blog is based on the successful operation of enterprise Micro-blog. Therefore, only by making reasonable marketing strategy of Micro-blog and making full use of the marketing value of Micro-blog, can enterprises play the role of Micro-blog marketing. Han (2015) states that Micro-blog marketing is a long and systematic process. Therefore, it is very important to evaluate the effect of Micro-blog marketing reasonably and give it timely feedback. However, how to formulate a more suitable Micro-blog marketing strategy for contemporary China will be the focus of future research and reality.

\section{REFERENCES}

[1] China Internet Network Information Center (CNNIC), No. 41 Statistical Report on Internet Development in China, CNNIC, Beijing.

[2] iResearch, 2018, Sina Micro-blog, viewed 28 April 2018, http://index.iresearch.com.cn/app/detail $\cdot i d=5 \& T i d=63$.

[3] H. Zhao, 'The driving factors of Micro-blog Marketing', Social Scientist, 2012, No.7 pp.79-81.

[4] H. Li \&Z. Xiang, 'An Analysis of Impacting Factor on Enterprises Micro-blog Marketing Effect-Taken XIAOMI as Example', Price Monthly, 2017, issue 11, pp.78-80

[5] M. Zhang \& H. Wang, 'Analysis on the limitation of Media Micro-blog Marketing', Journalism Lover, 2012, Issue 03, pp.73-74.

[6] L. Liu, 'On Micro-blog Marketing from the Perspective of Branding', Price Monthly, 2013, Issue 09, pp.72-75.

[7] Y. Chen, 'Micro-blog Marketing Dilemma Faced by Enterprises and Countermeasures', Reformation \& Strategy, 2015, Issue 1, pp.80-82.

[8] Isa, S.M, \& Wong K.Y. 2015, 'Age differences in behavioral intention to use internet marketing: a comparative study between Malaysian and Taiwanese', International Journal of Business and Society, Vol 16, No.3, pp.386-396

[9] Kuehn, K. R.\&R. P. Khanderkar \& C. R. Scott, The Effects of Marginality and Reward on Matrix Conflict, 1996, 27, No.3.

[10] Byounggu Choi, et al, 2004, Xiao Liu and Kwok Kee Wei, 2003.

[11] Aron O'Cass 2003, 'Tion Fenech. Web Retailing Adoption: Exploring the Nature of Internet Users Web Retailing Behavior [J]', Journal of Retailing and Consumer Service, 2003, No.10, pp. 81-94

[12] K. Han, 'Where Does Micro-blog Marketing Go', Enterprise Management, 2015, Issue 12, pp.109-110. 